\title{
Cost Effectiveness of Lumbar Epidural Steroid Injections Provides Inaccurate Information
}

\section{TO THE EDITOR:}

Carreon et al (1) presented results of cost effectiveness of lumbar epidural steroid injections from a tertiary surgical referral center. It is possible that these patients may have already failed epidural injections with expectation of surgical interventions with high levels of nocebo experiences and potential lack of medical necessity. Procedures were performed without regard to the relief criteria (2). The authors have omitted important trial references and modern day cost utility analyses.

Multiple pragmatic randomized controlled trials (RCTs) with 2-year follow-up and cost-utility analysis have been performed for epidural injections and other procedures. Manchikanti et al (3) showed cost utility of caudal epidural injections with only direct costs of $\$ 2,172.50$. Adding indirect costs at $40 \%$ yielded $\$ 3,628$ per QALY in 480 patients. Similar results were obtained with lumbar interlaminar epidural injections (4) with inclusion of 360 patients from RCTs with 2-year followup with direct costs of $\$ 1,976.58$ with total estimated costs of \$3,301 per QALY.

In conclusion, this study's inappropriate design, filtered application of cost utility analysis and conclusions only adds to the confusion of the discordant existing literature. This study would be more helpful it was based on the more diverse literature that is currently available

Laxmaiah Manchikanti, MD

Clinical Professor

Anesthesiology and Perioperative Medicine

University of Louisville, Louisville, Kentucky

Professor of Anesthesiology-Research

Department of Anesthesiology, School of Medicine
LSU Health Sciences Center, New Orleans, Louisiana Medical Director

Pain Management Center of Paducah

2831 Lone Oak Road

Paducah, KY 42003

E-mail: drlm@thepainmd.com

Ramsin Benyamin, MD

Medical Director

Millennium Pain Center, Bloomington, IL

Clinical Assistant Professor of Surgery

College of Medicine, University of Illinois

Urbana-Champaign, IL

1015 S. Mercer

Bloomington, IL 61701

E-mail: ramsinbenyamin@yahoo.com

Standiford Helm II, MD

Medical Director

The Helm Center for Pain Management Center

24902 Moulton Parkway, Suite 200

949-462-0560

Laguna Hills, CA 92637

E-mail: drhelm@thehelmcenter.com

Joshua A. Hirsch, MD

Vice Chief: Interventional Care

Massachusetts General Hospital

Associate Professor of Radiology

Harvard Medical School

Affiliate Senior Research Fellow

Neiman Health Care Policy Institute

55 Blossom St., Gray 241B

Boston, MA 02114

E-mail: HIrsch@snisonline.org

\section{References}

1. Carreon LY, Bratcher KR, Ammous F, Glassman SD. Cost-effectiveness of lumbar epidural steroid injections. Spine ( $\mathrm{Ph}$ ila Pa 1976) 2018;43:35-40.

2. Manchikanti L, Abdi S, Atluri Set al. An update of comprehensive evidencebased guidelines for interventional techniques of chronic spinal pain: Part II:
Guidance and recommendations. Pain Physician 2013;16:S49-283.

3. Manchikanti L, Falco FJE, Pampati V, et al. Cost utility analysis of caudal epidural injections in the treatment of lumbar disc herniation, axial or discogenic low back pain, central spinal stenosis, and post lumbar surgery syndrome. Pain
Physician 2013;16:E129-43.

4. Manchikanti L, Pampati V, Benyamin RM, Hirsch JA. Cost utility analysis of lumbar interlaminar epidural injections in the treatment of lumbar disc herniation, central spinal stenosis, and axial or discogenic low back pain. Pain Physician 2017;20:219-28. 